\title{
CARDIAC INFARCTION WITH BUNDLE BRANCH BLOCK
}

\author{
BY \\ W. SOMERVILLE AND PAUL WOOD
}

From the Institute of Cardiology, London

Received February 9, 1949

When cardiac infarction is complicated by bundle branch block, the electrocardiogram may or may not show the features characteristic of myocardial injury. Interference with conduction through the left branch of the bundle of His usually suppresses pathological Q waves and other RS-T segment or $T$ wave changes in the standard and unipolar limb leads and in chest leads; it may then be impossible to make a cardiographic diagnosis of cardiac infarction. When a conduction defect involves the right branch, however, cardiographic signs of cardiac infarction can, as a rule, still be recognized (Wilson et al., 1947).

The association of cardiac infarction and bundle branch block is not uncommon (Oppenheimer and Rothschild, 1917; Applebaum and Nicholson, 1935; Comeau et al., 1938; Fischer, 1938; Master et al., 1938; Moia and Acevedo, 1945). Since the majority of these reports were published, the use of multiple chest leads has permitted a higher degree of precision in the diagnosis of cardiac infarction and in the localization of intraventricular conduction defects, and it is likely that in the future the association of these two conditions will be diagnosed more frequently and with greater accuracy (Wilson et al., 1944). The subject is of considerable importance, not only from the viewpoint of practical diagnosis, but also because cardiac infarction complicated by bundle branch block has a mortality almost twice as great as that of infarction with normal intraventricular conduction (Master et al., 1938).

The object of this investigation was to determine the frequency with which the electrocardiographic signs of cardiac infarction could be recongized in the presence of bundle branch block and to discover what factors tended to prevent their suppression.

\section{MATERIAL}

The electrocardiograms and case-notes that form the basis of this report were obtained from the records of Hammersmith Hospital, the London Hospital, and the National Heart Hospital. The majority of the patients concerned, however, were examined and investigated by one or other of the writers. A number of patients who had been under observation before the war could not be subsequently traced. Follow-up studies are therefore incomplete.

Generally the diagnosis of cardiac infarction was based on a typical clinical history; when this was lacking, the diagnosis depended on $\mathrm{X}$ ray evidence of ventricular aneurysm or on the demonstration of an infarct at necropsy. Bundle branch block was recognized according to the criteria laid down by Wilson and his co-workers, namely:-

“... when the QRS interval measures 0.12 second or more and the QRS complex in lead $I$ is monophasic and consists of a broad, slurred, flattopped or bifid deflection, left bundle branch block is usually present. When the QRS interval measures $0 \cdot 12$ second or more and the QRS complex in lead $I$ is biphasic or triphasic and ends with a broad, slurred or notched $\mathrm{S}$ deflection the block is usually in the right bundle. When the heart is in the vertical position the limb leads may suggest that right branch block is present when the præcordial curves are characteristic of left branch block, and vice versa. When the QRS interval measures $0 \cdot 12$ second or more and the præcordial electrocardiogram shows some but not all of the features typical of right or left branch block the conduction defect cannot be located with certainty." (Wilson et al., 1944).

\section{RESULTS}

The present series consisted of 60 cases of cardiac infarction and bundle branch block, and was divided into two groups depending on whether the electro- 
cardiogram revealed evidence of both cardiac infarction and bundle branch block, or of bundle branch block only. The composition of the two groups is presented in Table $I$.

The main features of the 41 cases showing cardiographic evidence of both cardiac infarction and bundle branch block are set down in Table II.

\section{Cardiac Infarction and Left Bundle Branch BLOCK}

There were 33 cases with a clinical history of cardiac infarction and an electrocardiogram showing left bundle branch block. In sixteen of these (48 per cent) the cardiogram also revealed abnormal $\mathbf{Q}$ waves, RS-T segment deviations, or altered T waves characteristic of cardiac infarction.

The relative frequency of such signs in the various leads taken are set down in Table III (anterior infarction) and Table IV (posterior infarction).

\section{Anterior Infarction}

In experiments on dogs, Wilson and his coworkers have shown that when the left branch of the bundle of His is interrupted, direct leads from the epicardial surface of a left ventricular transmural infarct record the initial positive potential of the left ventricular cavity and therefore cannot show a $Q$ wave. When the infarct includes the ventricular septum, however, the initial negative potential of the endocardial surface of the right ventricle may be transmitted through the infarcted-and hence electrically inert-septum to the cavity of the left ventricle. Then leads facing the left ventricular surface may show an initial negative deflection (Q wave) characteristic of cardiac infarction (Wilson et al., 1944; Sodeman et al., 1944).
In all but one of the 12 cases in which a cardiographic diagnosis of anterior infarction was made, a $Q$ wave was present in lead $I$ and in leads taken over the left præcordium (Fig. 1). A similar change was found in the unipolar left arm lead (VL) in five of the six cases in which it was taken. When present in the left præcordial leads, $Q$ may be expected in leads I and VL, but cannot be guaranteed (Wilson, 1936; Master et al., 1938). Septal infarction was found in all three of our cases of left bundle branch block with a $Q$ in lead I that were examined post-mortem.

RS-T segment deviation in greater or less degree and abnormal $T$ waves usually accompanied abnormal $\mathrm{Q}$ waves (Fig. 2); only one example (Case 2) was encountered where a diagnosis of infarction could be made from the RS-T segment or $T$ wave in the absence of a $Q$ wave. Marked RS-T segment elevation and coving is a feature of fresh infarction with left bundle branch block as well as with normal conduction (Bach, 1930; Master et al., 1938; Vela, 1944; Moia and Acevedo, 1945; and others) and has been demonstrated experimentally in animals (Hill, 1934). For a time it may be the only clear sign of infarction, preceding the appearance of $\mathrm{Q}$, or the latter may be indistinct or fail to develop. It follows that if an electrocardiogram can be obtained within a few hours or days of infarction, a cardiographic diagnosis of infarction will be possible in a correspondingly higher proportion of cases despite the left bundle branch block. As a rule, however, the RS-T segment depression in lead I typical of left bundle branch block tends to neutralize the RS-T elevation of anterior infarction; and this segment is usually isoelectric or only slightly elevated or depressed (Fig. 2). RS-T segment elevation is not necessarily confined to the

TABLE I

Electrocardiographic Findings in 60 Cases of Bundle Branch Block with History or other Evidence of CARDIAC INFARCTION

\begin{tabular}{|c|c|c|c|c|c|c|c|c|c|c|c|}
\hline \multirow[b]{2}{*}{ Electrocardiogram } & \multicolumn{2}{|c|}{ Sex } & \multirow[b]{2}{*}{$\begin{array}{l}\text { Age } \\
\text { (av.) }\end{array}$} & \multicolumn{4}{|c|}{ Left bundle branch block } & \multicolumn{4}{|c|}{ Right bundle branch block } \\
\hline & Male & Female & & Ant. & Post. & $\begin{array}{l}\text { Ant. } \\
\text { and } \\
\text { post. }\end{array}$ & Total & Ant. & Post. & $\begin{array}{l}\text { Ant. } \\
\text { and } \\
\text { post. }\end{array}$ & Total \\
\hline $\begin{array}{c}\text { Cardiac infarction and } \\
\text { bundle br. block (41 } \\
\text { cases) }\end{array}$ & 35 & 6 & 60 & 12 & 4 & 0 & 16 & 14 & 10 & 1 & 25 \\
\hline $\begin{array}{l}\text { Bundle br. block only } \\
\text { (19 cases) } \ldots\end{array}$ & 15 & 4 & 63 & 一 & 一 & 一 & 17 & 一 & - & 一 & 2 \\
\hline Total (60 cases) & 50 & 10 & $61 \cdot 5$ & - & 一 & 一 & 33 & 一 & 一 & - & 27 \\
\hline
\end{tabular}


TABLE II

Cases of Cardiac Infarction showing Electrocardiographic Evidence of both Cardiac Infarction and BUNDLE BRANCH BLOCK

\begin{tabular}{|c|c|c|c|c|c|c|c|c|c|c|}
\hline \multirow[b]{2}{*}{$\begin{array}{l}\text { Case } \\
\text { No. }\end{array}$} & \multirow[b]{2}{*}{ Sex } & \multirow[b]{2}{*}{ Age } & \multirow[b]{2}{*}{$\begin{array}{l}\text { Date of } \\
\text { infarct. }\end{array}$} & \multirow{2}{*}{$\begin{array}{l}\text { Date of } \\
\text { electro- } \\
\text { cardio- } \\
\text { gram }\end{array}$} & \multicolumn{6}{|c|}{ Electrocardiogram } \\
\hline & & & & & Leads taken ${ }^{2}$ & $\begin{array}{l}\text { QRS } \\
\text { (sec.) }\end{array}$ & $\begin{array}{c}\text { Abnormal } \\
\mathbf{Q}\end{array}$ & $\begin{array}{l}\text { Deviation } \\
\text { of RS-T }\end{array}$ & $\begin{array}{l}\text { Abnor- } \\
\text { mal T }\end{array}$ & $\begin{array}{l}\text { Site of } \\
\text { infarct at } \\
\text { necropsy }\end{array}$ \\
\hline
\end{tabular}

Left Bundle Branch Block: Anterior Infarction

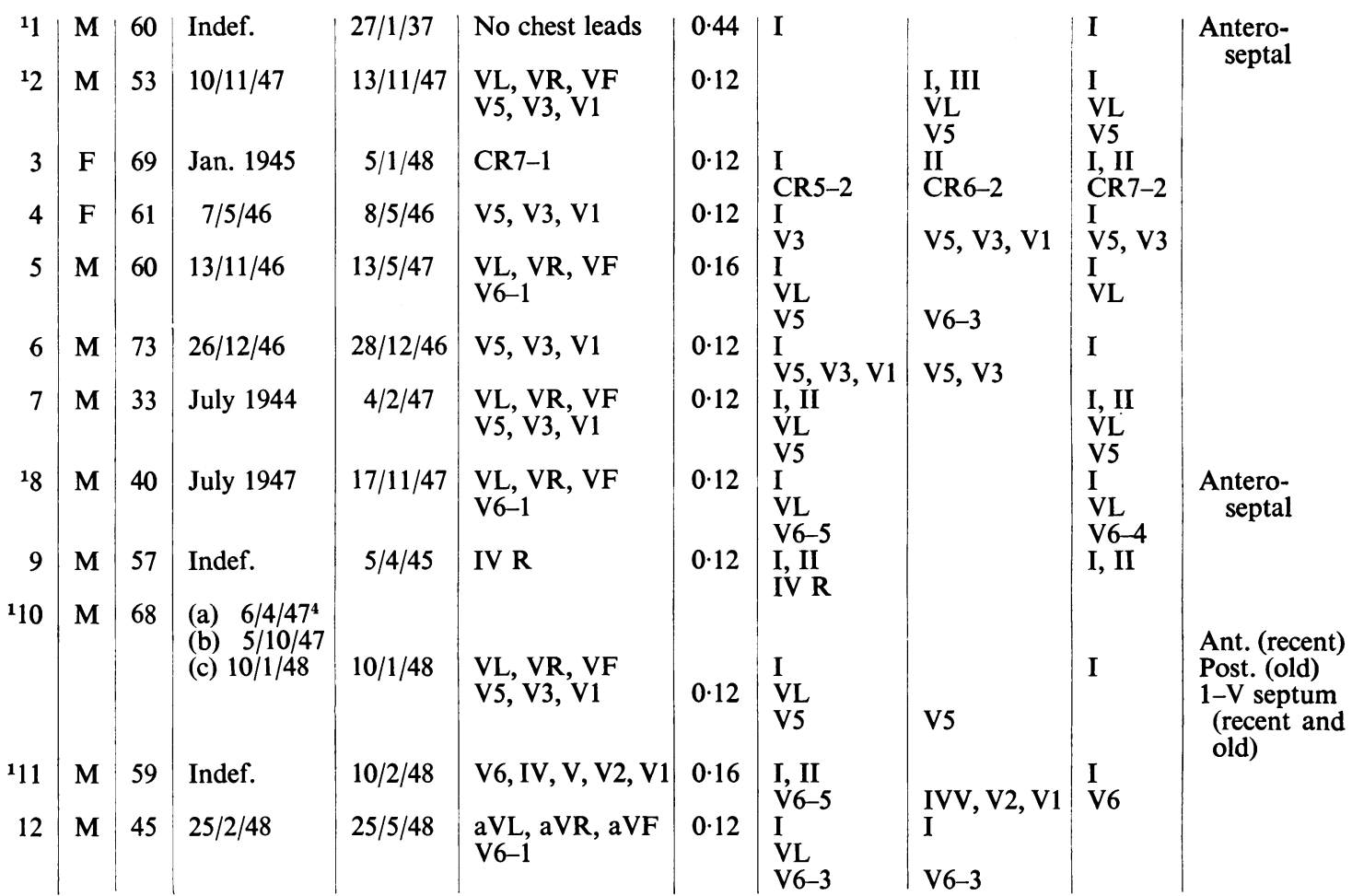

Left Bundle Branch Block: Posterior Infarction

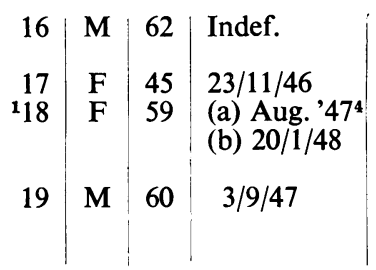

\begin{tabular}{|c|l}
$2 / 8 / 46$ & CR7, CR4 \\
$27 / 11 / 46$ & V5, V3, V1 \\
22/1/48 & V5, VR, V3, V1 \\
9/9/47 & VL, VR, VF \\
& V5, V3, V1
\end{tabular}

\begin{tabular}{|l|l|}
$0 \cdot 12$ & II, III \\
& CR7, CR4 \\
$0 \cdot 12$ & III \\
$0 \cdot 14$ & II, III \\
& VF \\
$0 \cdot 12$ & II, III \\
& VF
\end{tabular}

III
III
I, II, III
VL, VF
V55
I, II, III
V5

$\left|\begin{array}{l}\text { III } \\ \text { III } \\ \text { II, III } \\ \text { VF } \\ \text { II, III } \\ \text { V1 } \\ \text { VF }\end{array}\right|$

Right Bundle Branch Block: Anterior Infarction

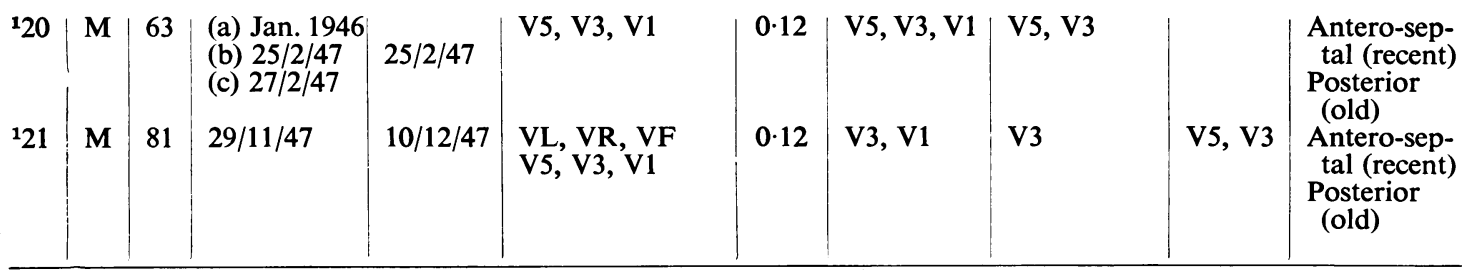


TABLE II--continued

\begin{tabular}{|c|c|c|c|c|c|c|c|c|c|c|}
\hline \multirow[b]{2}{*}{$\begin{array}{c}\text { Case } \\
\text { No. }\end{array}$} & \multirow[b]{2}{*}{ Sex } & \multirow[b]{2}{*}{ Age } & \multirow[b]{2}{*}{$\begin{array}{l}\text { Date of } \\
\text { infarct }\end{array}$} & \multirow{2}{*}{$\begin{array}{l}\text { Date of } \\
\text { electro- } \\
\text { cardio- } \\
\text { gram }\end{array}$} & \multicolumn{6}{|c|}{ Electrocardiogram } \\
\hline & & & & & Leads taken ${ }^{2}$ & $\begin{array}{l}\text { QRS } \\
\text { (sec.) }\end{array}$ & $\begin{array}{c}\text { Abnormal } \\
\mathbf{Q}\end{array}$ & $\begin{array}{l}\text { Deviation } \\
\text { of RS-T }\end{array}$ & $\begin{array}{l}\text { Abnor- } \\
\text { mal T }\end{array}$ & $\begin{array}{c}\text { Site of } \\
\text { infarct at } \\
\text { necropsy }\end{array}$ \\
\hline
\end{tabular}

Right Bundle Branch Block: Anterior Infarction-continued

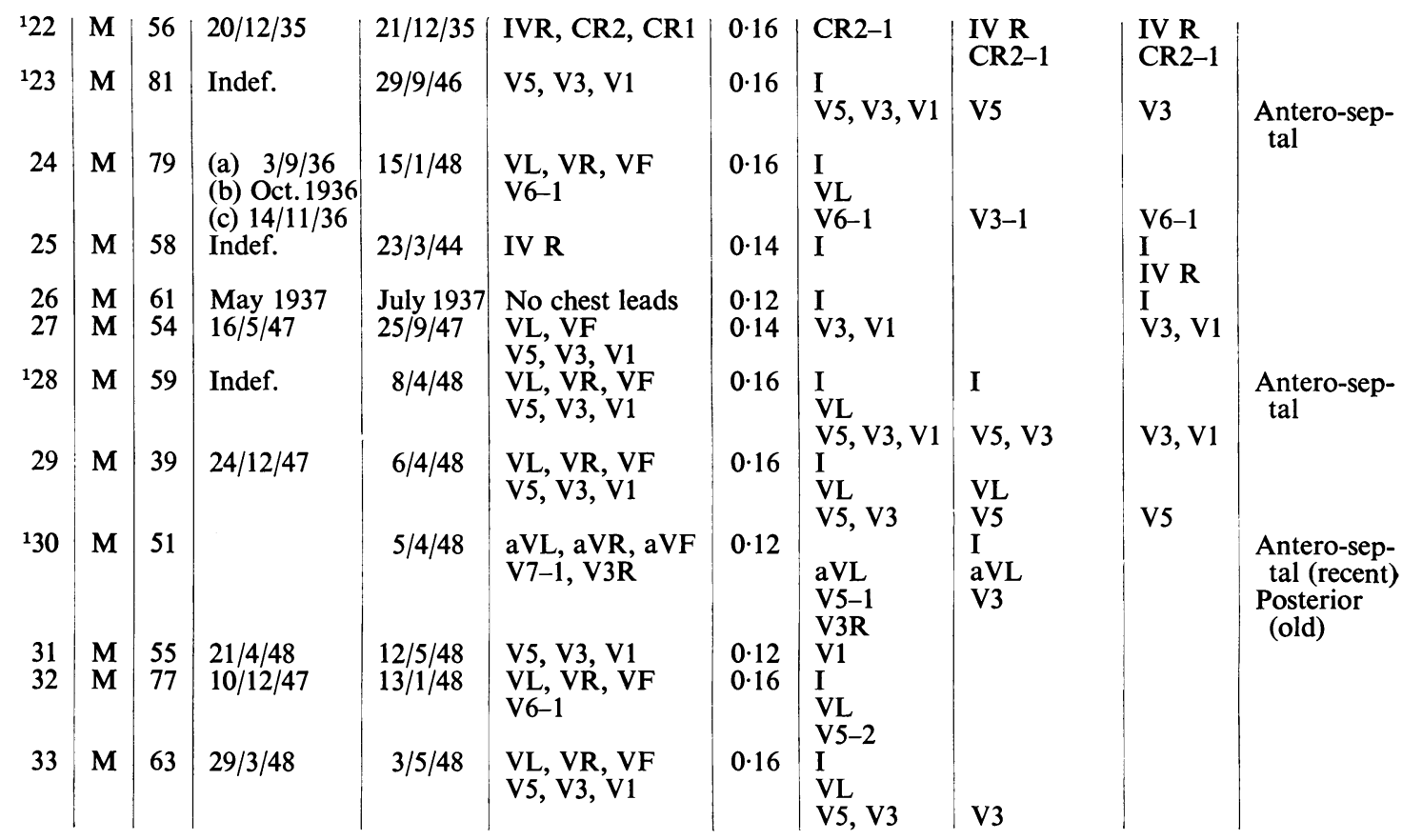

Right Bundle Branch Block: Posterior Infarction

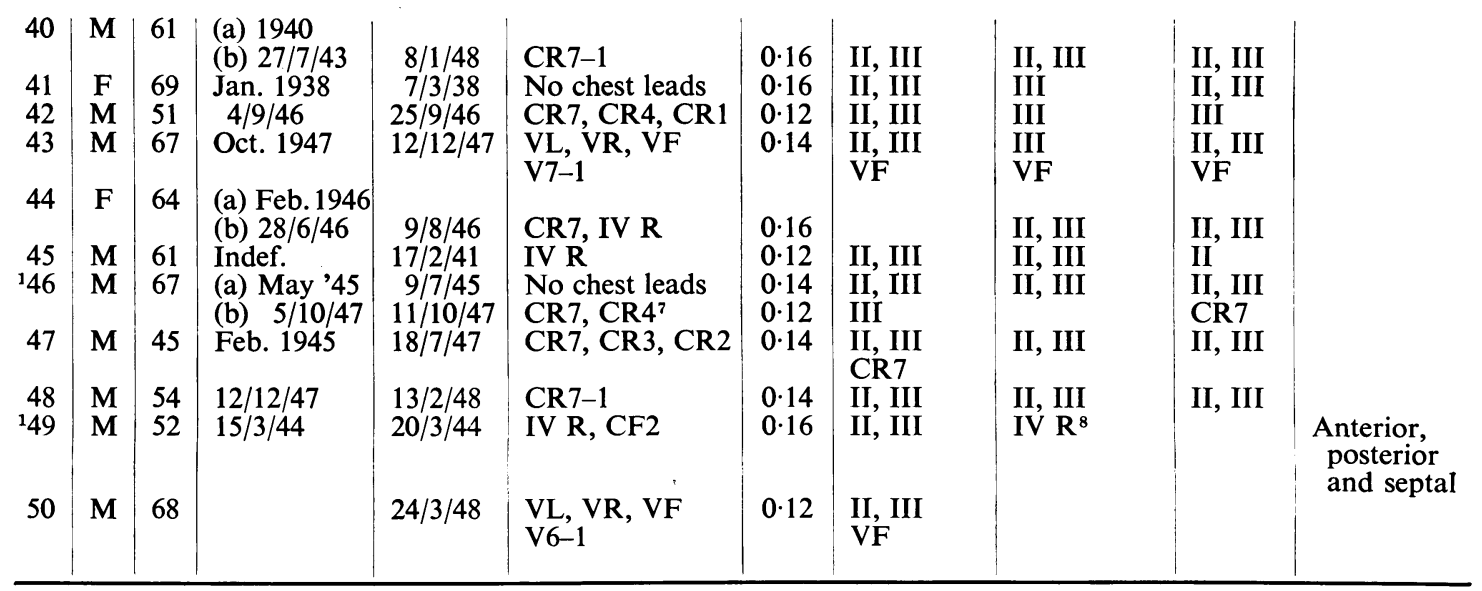

${ }^{1}$ Dead. $\quad{ }^{2}$ Standard limb leads were taken in all cases. $\quad{ }^{3}$ " Anterior" and "Posterior" refer to left ventricle.

4 Electrocardiogram showed posterior infarction with normal intraventricular conduction.

${ }^{5}$ Marked depression of RS-T segment. ${ }^{6}$ Abnormally tall T waves present in lead VI.

${ }^{7}$ Left bundle branch block. ${ }_{8}^{8}$ In IV R, QRS and RS-T segment indicated involvement of apical region. 
TABLE III

EleCtrocardiographic SignS OF ANTERIOR INFARCTION COMPLICATED BY LEFT BUNDLE BRANCH BLOCK

Abnormal Q

11

9

5

RS-T Deviation Standard limb leads (12 cases)

$$
3
$$

\section{TABLE IV}

EleCtrocardiographic SignS OF POSTERIOR INFARCTION COMPLICATED BY LeFT BundLE BRANCH BLOCK

\begin{tabular}{|c|c|c|}
\hline $\begin{array}{c}\text { Abnormal Q } \\
4\end{array}$ & $\begin{array}{c}\text { RS-T Deviation } \\
\text { Standard limb leads (4 cases) } \\
44\end{array}$ & $\begin{array}{c}\text { Abnormal T } \\
4\end{array}$ \\
\hline 1 & Chest leads (4 cases) & 1 \\
\hline 2 & Unipolar limb leads (2 cases) & 2 \\
\hline
\end{tabular}

acute stages of the infarct but may persist for months or years. In eight of our twelve cases in this group, prominent RS-T elevation in lead I and/or the left chest leads was present for 2 days (Case 10), 9 days (Case 4), 2 weeks (Cases 2 and 6), 2-3 months (Cases 11 and 12), and 6 months (Case 5). In the eighth case conspicuous RS-T segment deviation was still evident in leads CR5-2 three years after the infarct (Fig. 3A) and in Case 11 in leads V4-2 five years after the infarct (Fig. 3B). Persistent RS-T deviation has been described as a sign of cardiac aneurysm (Nordenfelt, 1939; Wilson et al., 1944b), but this could not be detected in any of our cases.

Primary $\mathrm{T}$ wave changes associated with anterior cardiac infarction usually cannot be recognized in the presence of left bundle branch block, for the latter produces strong $T$ wave inversion in lead $I$ and in leads taken over the left ventricle. In no case did we feel justified in making a diagnosis of cardiac infarction by virtue of $\mathrm{T}$ wave changes alone.

Care must be taken in interpreting chest lead curves taken from positions $\mathrm{C} 1$ and $\mathrm{C} 2$ in uncomplicated left bundle branch block since these leads

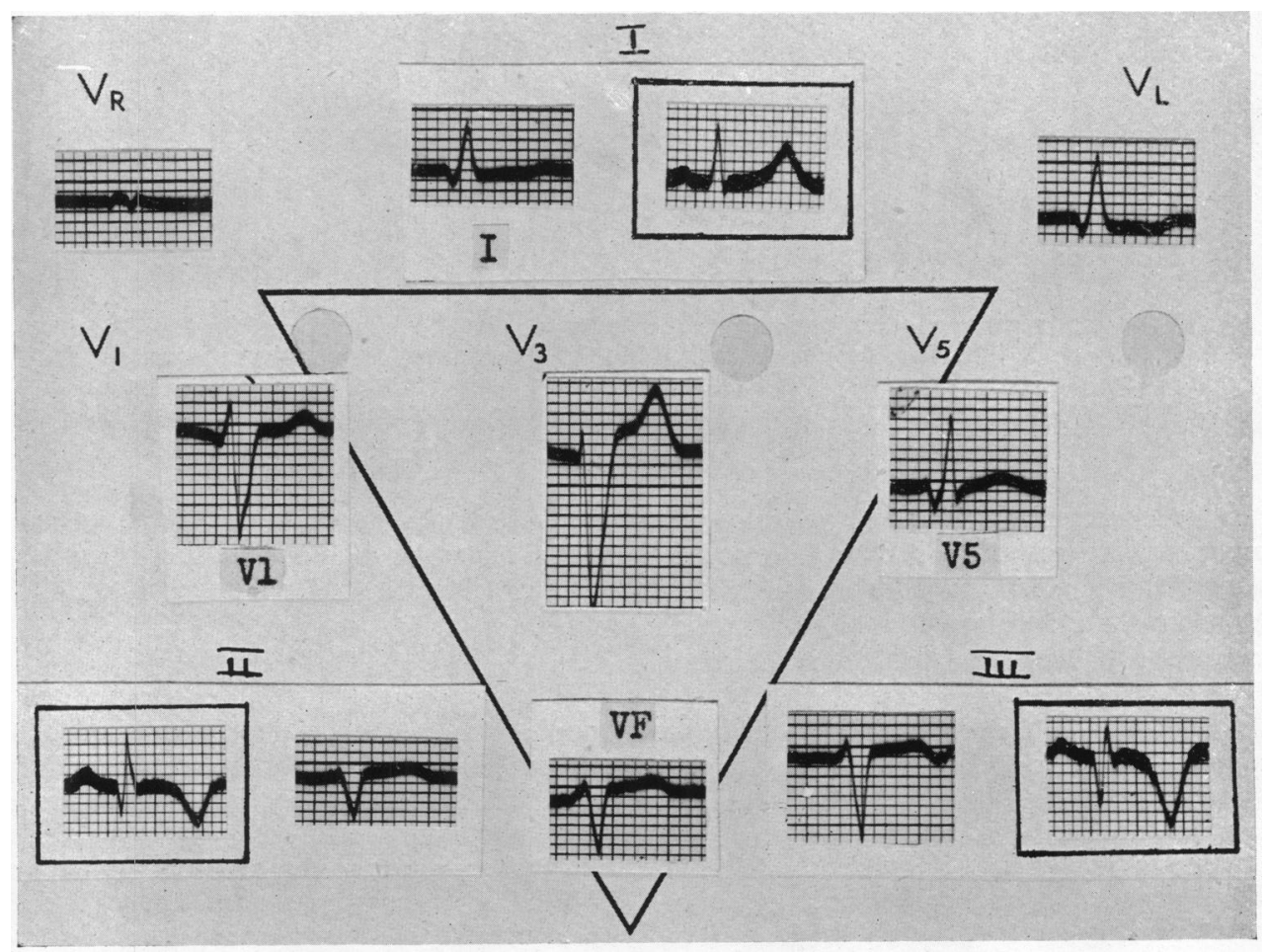

FIG. 1.-Anterior cardiac infarction and left bundle branch block. Previous standard leads, outlined in black, show the original posterior infarct. A prominent $Q$ wave due to involvement of the septum is seen in lead V5, and is transmitted to lead VL and to standard lead I. Autopsy confirmation. 


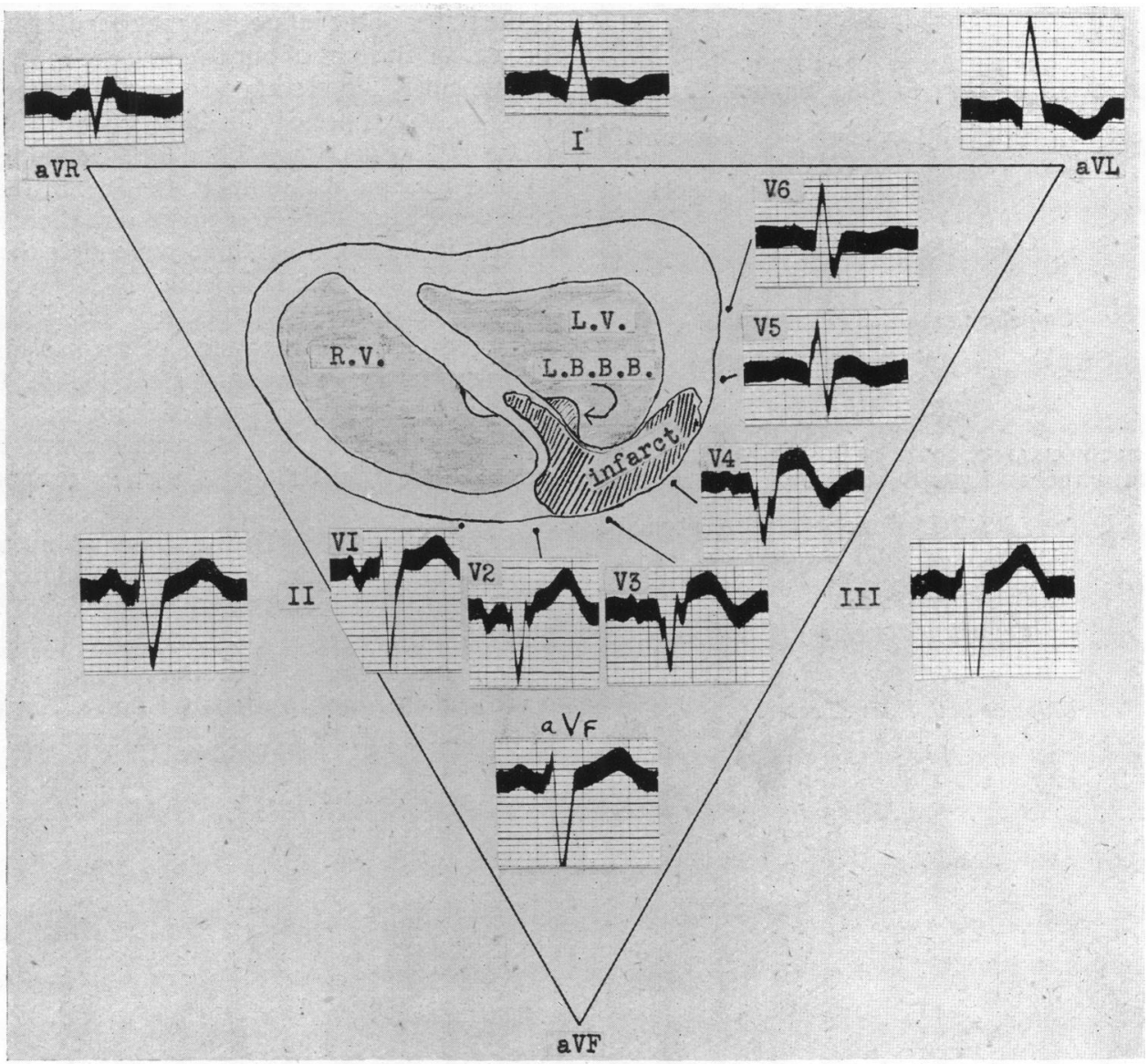

FIG. 2.-Anterior cardiac infarction and left bundle branch block. Elevation of the RS-T segment due to the infarct, seen best in leads V3 and V4, neutralizes any tendency towards RS-T depression due to left bundle branch block: thus in leads VL and standard lead I the RS-T segment is at the isopotential level. The small $Q$ wave in these two leads is due to septal infarction. Autopsy confirmation.

may show an inconspicuous $\mathrm{R}$ wave or may consist of a monophasic downward deflection followed by an elevated RS-T segment more or less simulating recent anterior or antero-septal infarction. Such complexes are sometimes known as " false infarction curves" (Mortensen, 1940).

Convincing evidence that left bundle branch block may suppress the signs of infarction was obtained in certain cases in which the block was transient (Fig. 4), or intermittent (Fig. 5).

Cardiographic signs of cardiac infarction obscured by left bundle branch block may be unmasked when a premature ventricular contraction originating on the blocked side allows both ventricles to contract simultaneously. Wilson and Herman (1921) were able to demonstrate the presence of an infarct in the experimental animal by this means and explained the physiological mechanism. We have encountered several examples of this type and others have been reported (Dressler, 1943; Simonson et al., 1945).

\section{Posteriar Infarction}

When posterior infarction is complicated by left bundle branch block, the appearance of characteristic $Q$ waves depends, as in anterior infarction, on the transmission of the initial negative potential of the right ventricular cavity through an infarcted ventricular septum to the cavity of the left ventricle. This initial negativity is then transmitted through the electrically inert posterior infarct to lead VF, and so to leads II and III. But QIII is also seen in at least one-third of cases of uncomplicated left bundle branch block (Sodeman et al., 1944).

In the four examples of posterior infarction that 
A

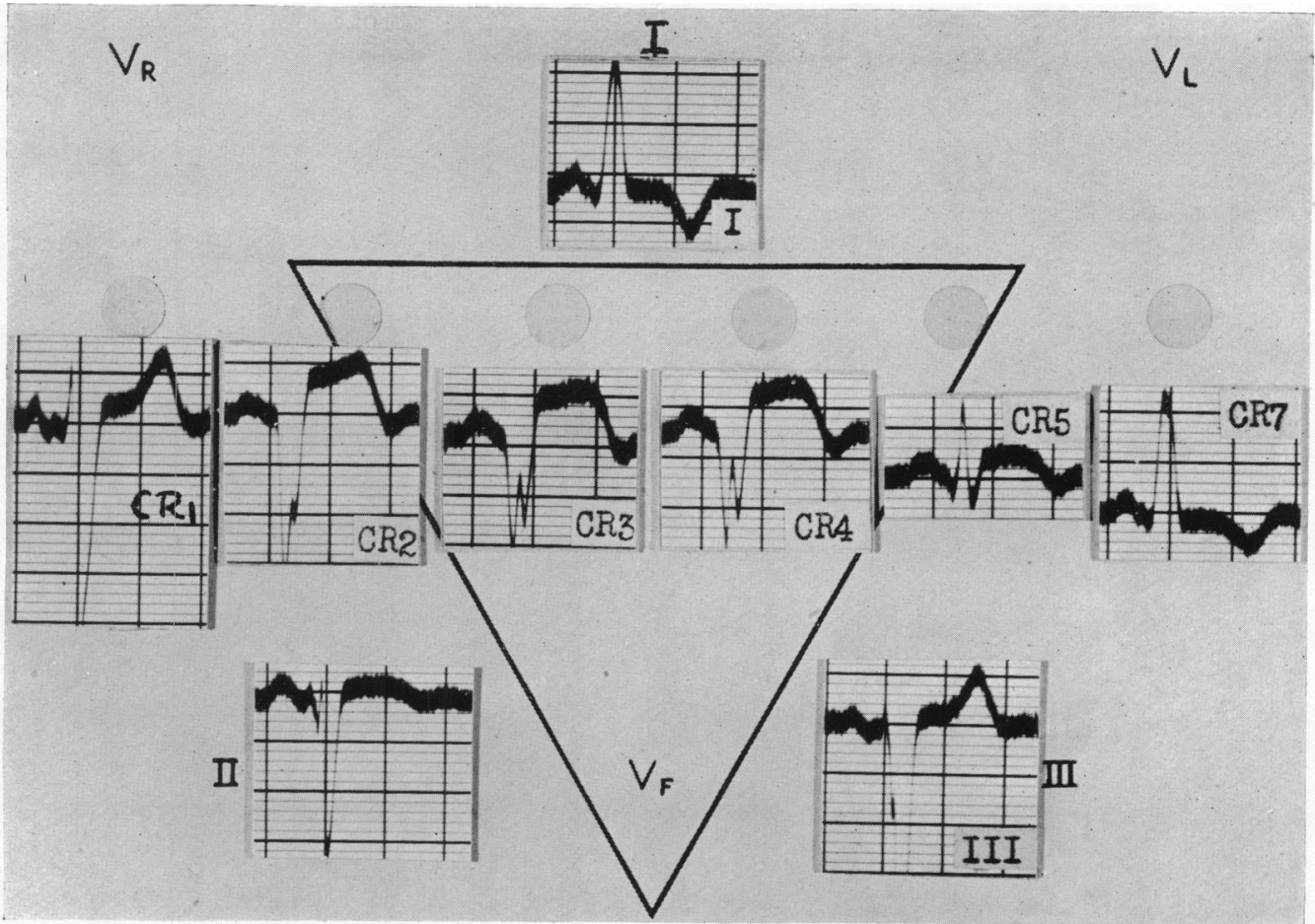

B

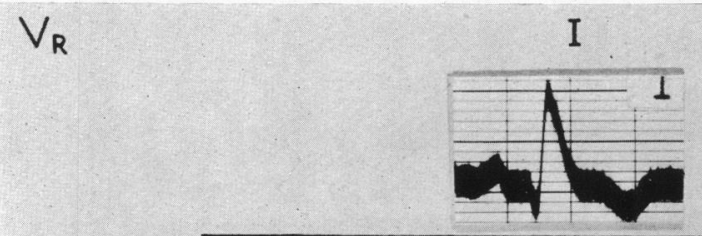

$\underline{\underline{m}}$

I

$\stackrel{2}{2}$

$\vec{\Rightarrow}$

뭄

듬

뭉

$\overrightarrow{0}$

$\overrightarrow{\vec{\omega}}$

㝏

ま

$\vec{\exists}$

$\dot{+}$

फ

으

$\rightarrow$

웅

웅

$\mathbb{D}$

$\overrightarrow{0}$

만

ํㅣㄴ

응

윽

감

‥

จำ

$\stackrel{2}{\rightrightarrows}$

응

올

음

궁

ㄱ.

N

N

N

three years after the infarct in example (A), and five years after the infarct in example (B), best shown in leads CR4 and V4 respectively. The $Q$ wave in left ventricular surface leads or their equivalents in both cases is due to septal infarction. 


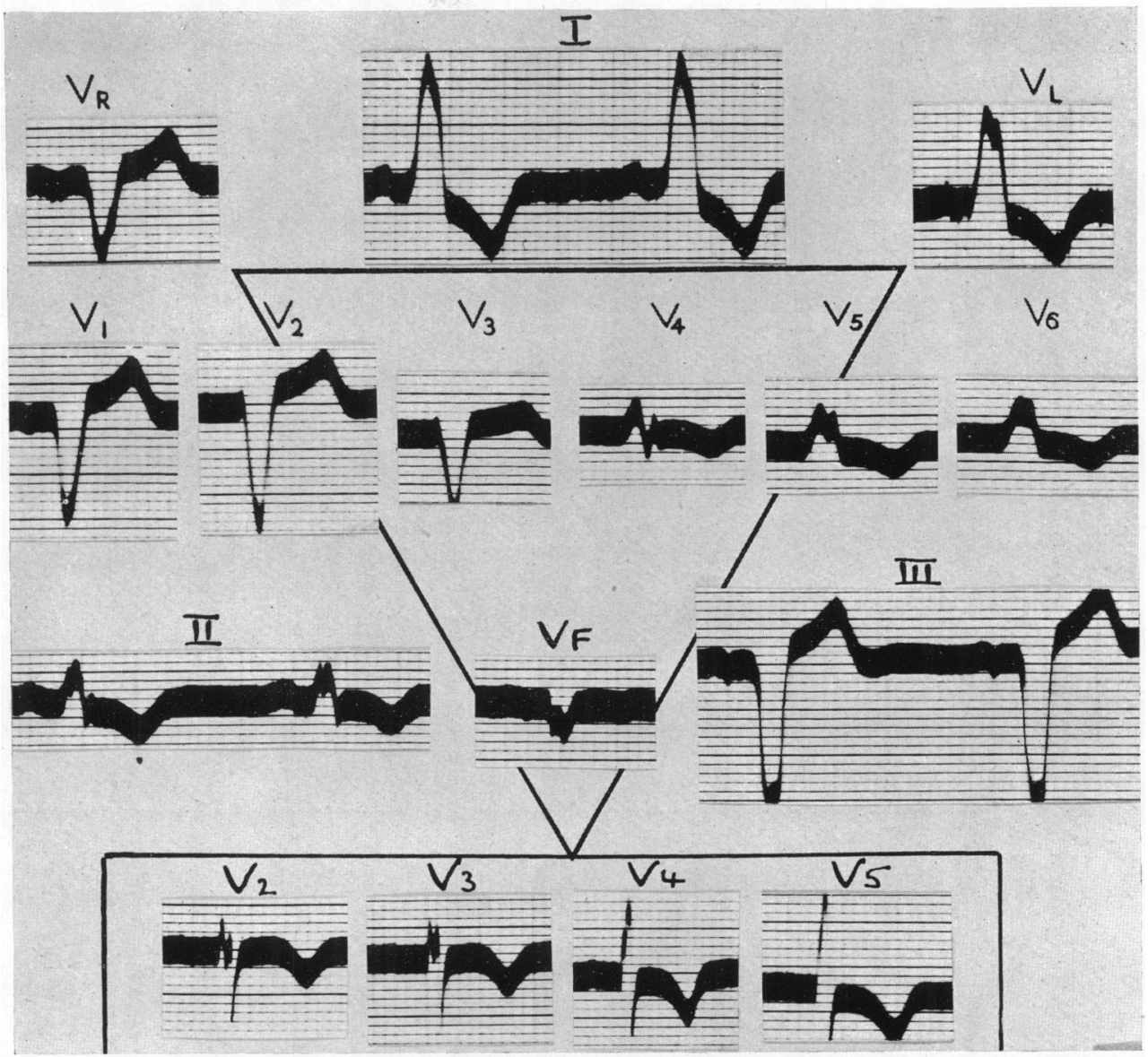

FIG. 4.-Transient left bundle branch block suppressing the signs of anterior cardiac infarction. When conduction was normal (shown below) the T waves were inverted from V2 to V5.

could be diagnosed cardiographically in this series, characteristic Q, RS-T, and T wave changes occurred in lead III. In one instance the curves were taken within a few hours of the onset and revealed RS-T segment elevation in leads II, III, and VF, with reciprocal depression in leads $I$, VL, and V5 (Fig. 6). Proof of septal involvement in these cases is lacking; three of them recovered, and the fourth did not come to necropsy. On the other hand, extensive posterior infarction not involving the septum was demonstrated at necropsy in Case 75. The cardiogram (standard limb leads and IV R) showed left bundle branch block without the signs of posterior infarction.

\section{Comment}

When the different factors are evaluated that tend to permit or suppress the signs of infarction complicated by left bundle branch block, which are discussed below, one may conclude tentatively that in about one-half of such cases cardiographic confirmation of the infarction will be forthcoming; in the other half, as long as the bundle branch block persists, the cardiographic signs of infarction will be suppressed. The diagnosis must then depend on the history and other clinical evidence.

\section{Cardiac Infarction and Right Bundle Branch BLOCK}

When right bundle branch block is present the sequence of depolarization of the ventricles is the same as when intraventricular conduction is normal. At the start of ventricular excitation the left ventricular cavity is negative and an infarct should transmit this initial negative potential to the surface in the usual way. Therefore the characteristic $\mathbf{Q}$ wave of cardiac infarction should not be suppressed.

In our series there were 27 cases of cardiac infarction complicated by right bundle branch block. 


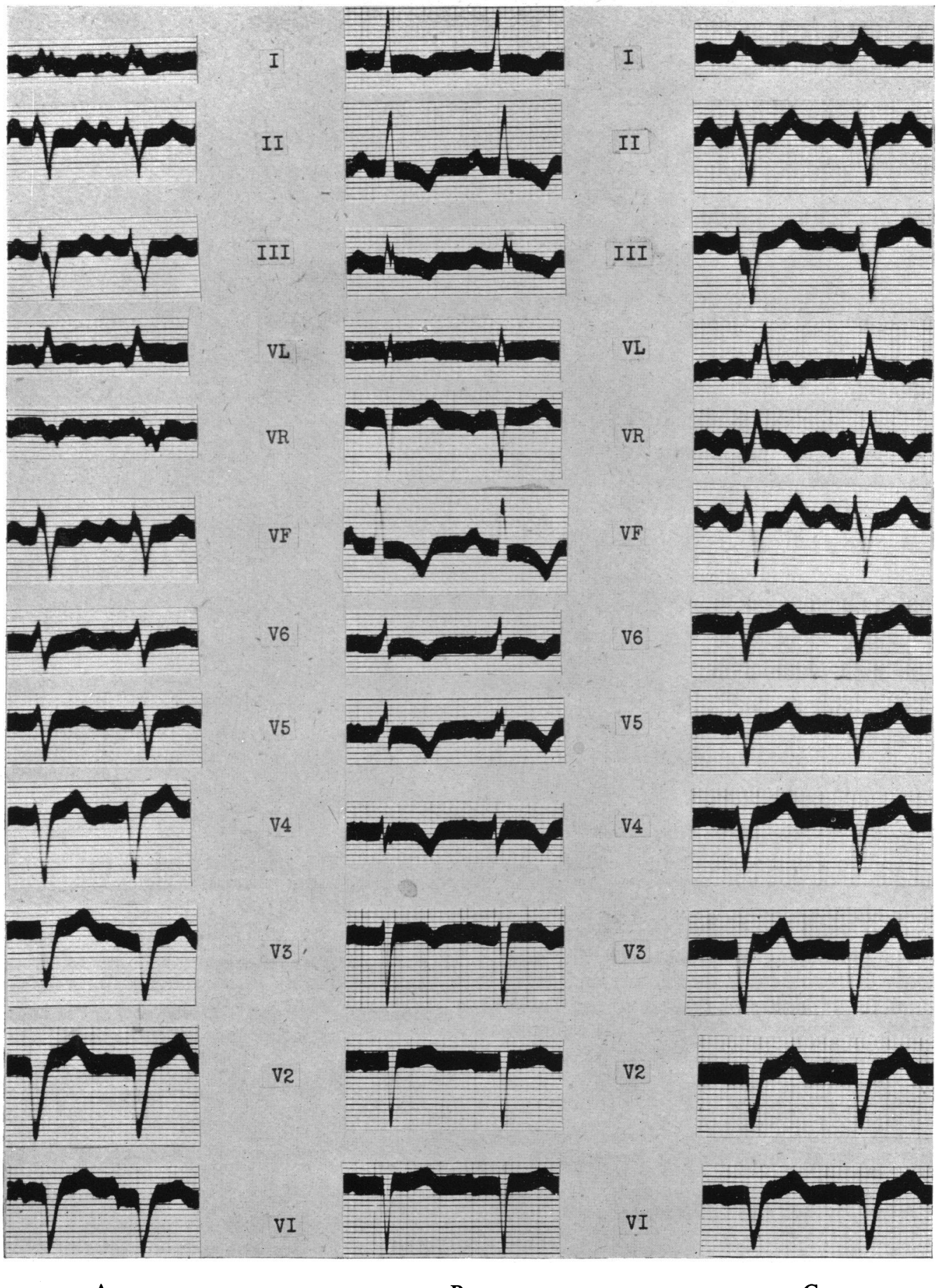

A

B

C

Fig. 5.- Intermittent left bundle branch block (A and C) suppressing the signs of anterior cardiac infarction. When conduction was normal (B), primary $T$ wave inversion of coronary type was seen from V3-V6. As the heart is electrically vertical, this inversion is transmitted to lead VF and hence to all standard leads. 


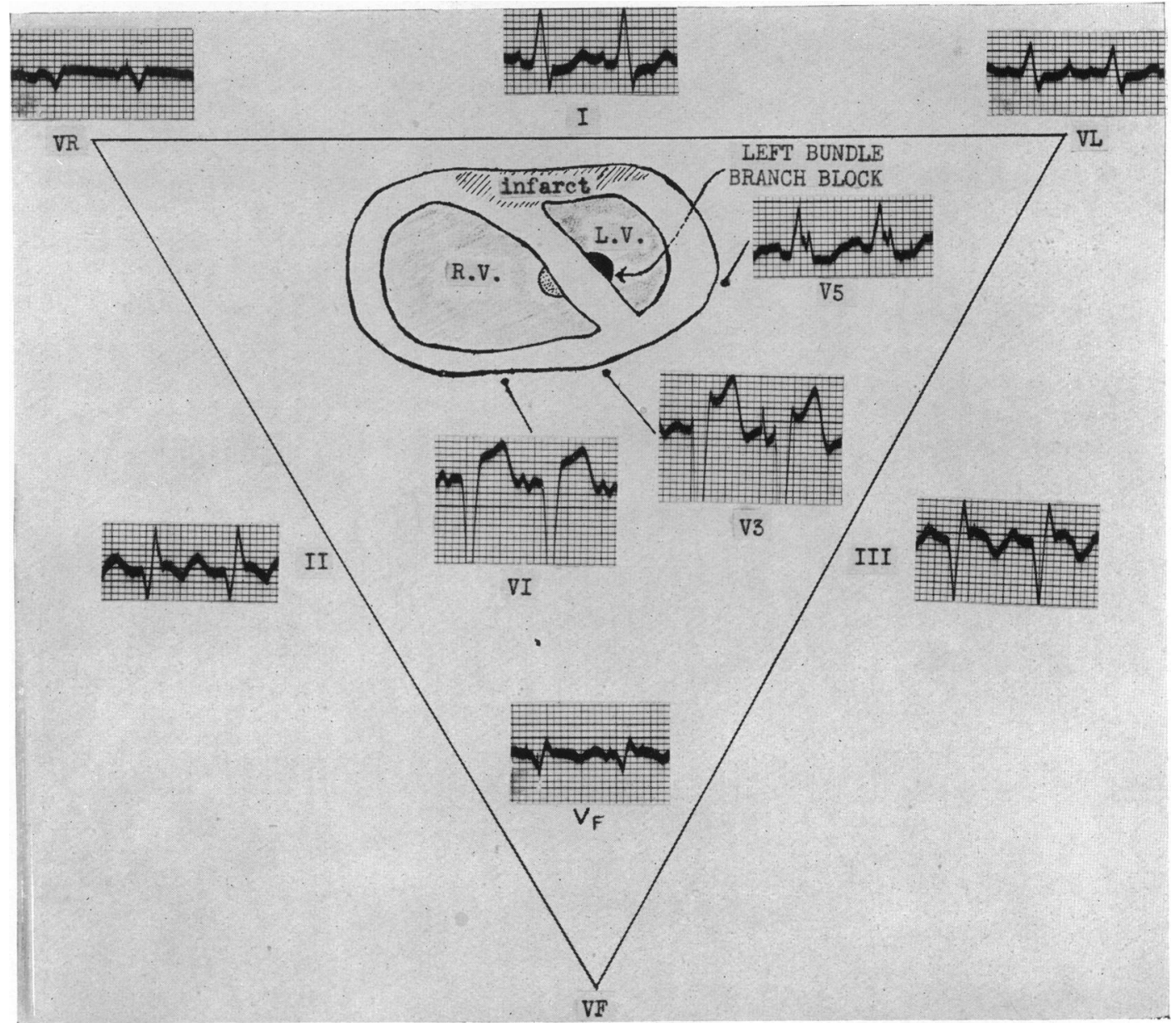

Fig. 6.-Posterior cardiac infarction and left bundle branch block. This graph was taken within a few hours of the onset, and shows characteristic changes denoting recent posterior infarction.

The cardiographic signs of cardiac infarction were present in 25 cases, i.e. in 93 per cent. The relative frequency of these signs in the various leads taken is shown in Table V (anterior infarction) and Table VI (posterior infarction). In six cases the infarct was confirmed at necropsy.

\section{TABLE V}

Electrocardiographic Signs of ANTERIOR INFARCTION CoMplicated BY Right BUNDLE BRANCH BLOCK

\begin{tabular}{|c|c|c|}
\hline $\begin{array}{c}\text { Abnormal Q } \\
8\end{array}$ & $\begin{array}{l}\text { RS-T Deviation } \\
\text { Standard limb leads (14 cases) } \\
\qquad 2\end{array}$ & $\begin{array}{c}\text { Abnormal T } \\
1\end{array}$ \\
\hline 12 & Chest leads (12 cases) & 7 \\
\hline 6 & Unipolar limb leads (8 cases) & 0 \\
\hline
\end{tabular}

\section{TABLE VI}

Electrocardiographic SignS of Posterior Infarction Complicated by Right Bundle BRanch Block

$\begin{gathered}\text { Abnormal Q } \\ 10\end{gathered} \begin{gathered}\text { RS-T Deviation } \\ \text { Standard limb leads (11 cases) }\end{gathered}$
$\begin{gathered}\text { Chest leads (9 cases) } \\ 1\end{gathered}$
$2 \quad \begin{gathered}\text { Unipolar limb leads (2 cases) } \\ 1\end{gathered}$
ANTERIOR INFARCTION
Eight of the fourteen cases of anterior infarction
showed characteristic Q waves in the standard limb
leads (Fig. 7). This is contrary to the experience
of Wilson et al. (1944), Carlotti (1947), and of
Goldberger (1947). RS-T segment deviation and




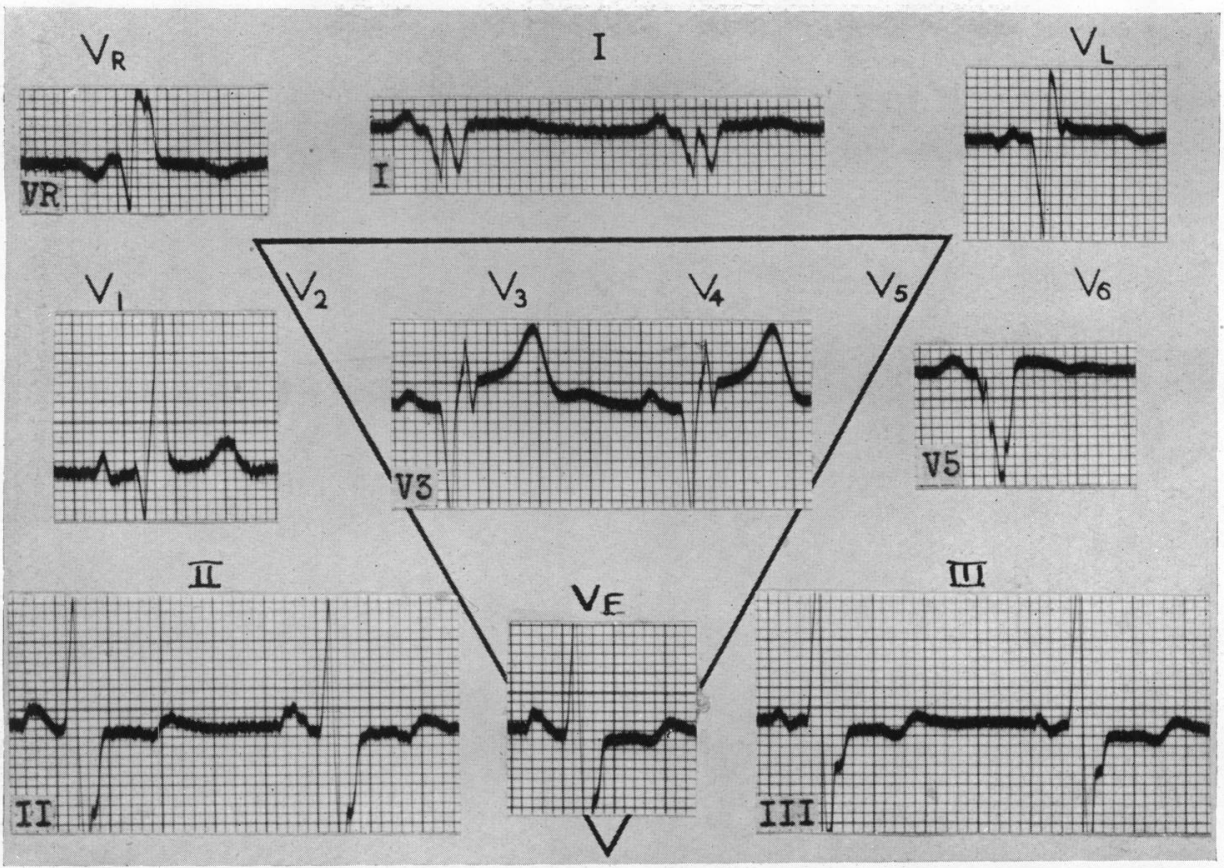

Fig. 7.-Anterior cardiac infarction and right bundle branch block. Typical $\mathrm{Q}$ waves are seen in leads V3, V5, VL and standard lead I.

primary $\mathrm{T}$ wave changes were commonly absent from the standard limb leads: thus in the six cases showing no Q I, these leads failed absolutely to show the infarct (Fig. 8 and 10).

Multiple chest leads were diagnostic of infarction in the twelve cases in which they were recorded, $Q$ waves being invariably present, and RS-T and $T$ wave changes occurring in the majority (Fig. 9).

The unipolar left arm lead reproduced the $Q$ wave of anterior infarction in six out of eight cases (Fig. 9). RS-T and $T$ wave changes were seldom diagnostic.

In Case 22 (Fig. 10A) no cardiographic evidence of infarction was present six hours after an attack typical of coronary thrombosis. On the following day right bundle branch block (QRS interval measuring $0.16 \mathrm{sec}$.) had developed; evidence of infarction was then obvious in the chest leads but not in the limb leads. The next record, taken nine days later when normal intraventricular conduction had returned, showed the pattern of anterior or antero-septal infarction in lead I and in the chest leads. Serial cardiograms during the next fourteen months revealed gradual reversion towards normal, but monophasic negative initial ventricular complexes persisted in leads CR2 and CR1.

The cardiogram shown in Fig. 10B was taken a few hours after the onset of a prolonged attack of cardiac pain in a man aged 63 (Case 20) and dis- closed right bundle branch block. Diagnostic evidence of extensive anterior infarction was provided by chest leads, but not by limb leads. At necropsy there was a recent infarct involving a large area of the anterior wall of the left ventricle and of the ventricular septum, and an old posterior infarct.

The chest leads in Case 23 (Fig. 11A) showed prominent $\mathrm{Q}$ waves in leads $\mathrm{V} 5, \mathrm{~V} 3$, and $\mathrm{V} 1$, in addition to the features of right bundle branch block. The complex recorded over the right præcordium (VI) resembled that in lead I, while V5 resembled lead III. Therefore, the heart was electrically vertical. At necropsy a recent infarct was found involving the apex and the lower portion of the ventricular septum. The explanation of the tall $R$ waves following deep $Q$ waves seen in chest leads in cases of anterior infarction associated with right bundle branch block is obscure, because as Goldberger has pointed out (1947), the deep Q wave indicates that the lead in question is facing the infarcted left ventricle, whereas the tall $R$ wave ordinarily occurs in leads that face the epicardial surface of the right ventricle in right bundle branch block.

The cardiograms reproduced in Fig. 11B (Case 21) are those of an old man of 81 who developed symptoms of cardiac infarction eleven days previously. The unipolar limb leads showed the heart 


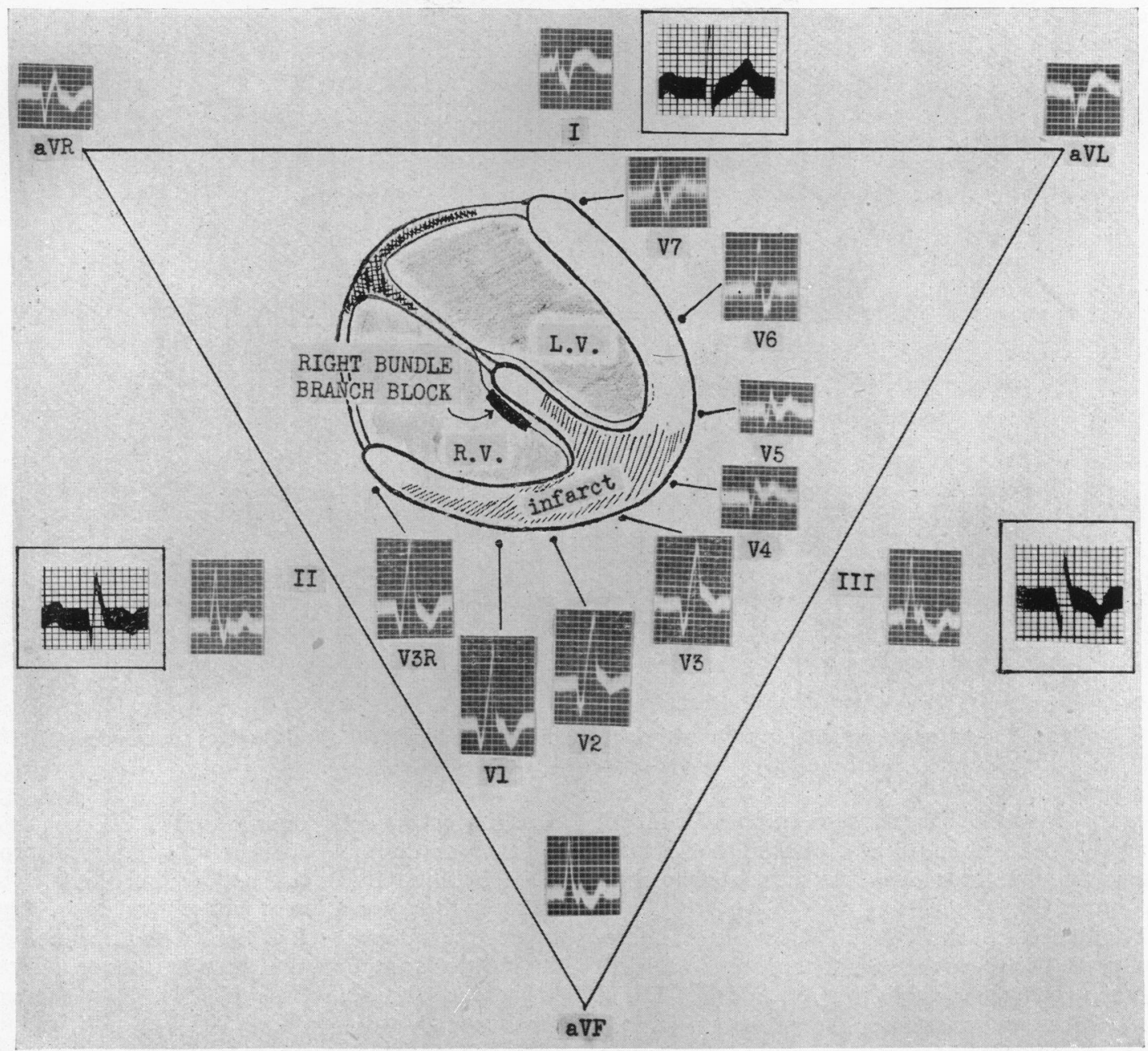

FIG. 8.-Anterior cardiac infarction and right bundle branch block. Typical $Q$ waves are seen in the chest leads, but the standard leads reveal no evidence of the infarct. Standard leads outlined in black were taken previously and represent old posterior infarction. Autopsy confirmation.

to be electrically vertical, and the chest leads pointed to a block in the right bundle branch. Conspicuous deviation of the RS-T segment was seen in lead V3 and small $Q$ waves were present in this lead and in lead V1. The diagnosis was, therefore, right bundle branch block complicating an antero-septal infarct. The patient died a week later and at necropsy this diagnosis was confirmed. In addition an old posterior infarct was demonstrated.

\section{Posterior Infarction}

When posterior infarction was associated with right bundle branch block, standard limb leads showed characteristic changes in all 11 cases (Fig. 12). Unipolar limb leads were obtained in only two instances (Cases 43 and 50): lead VF showed significant $Q$ waves in both, with elevation of the RS-T segment and inversion of the $T$ wave in one of them. Multiple chest leads were taken in 9 cases, but revealed evidence of infarction in only one instance.

When the posterior wall of the left ventricle is infarcted, and normal intraventricular conduction is present, the $T$ wave in lead CR7 is usually inverted (Evans and Hunter, 1943). Although there is no apparent reason why a complicating right bundle branch block should suppress the characteristics of posterior infarction in this lead, an upright $\mathrm{T}$ wave was present in lead CR7 in five cases, and in V7 in a fourth (Fig. 12 and 13B). The $T$ wave in $C R 7$ was 


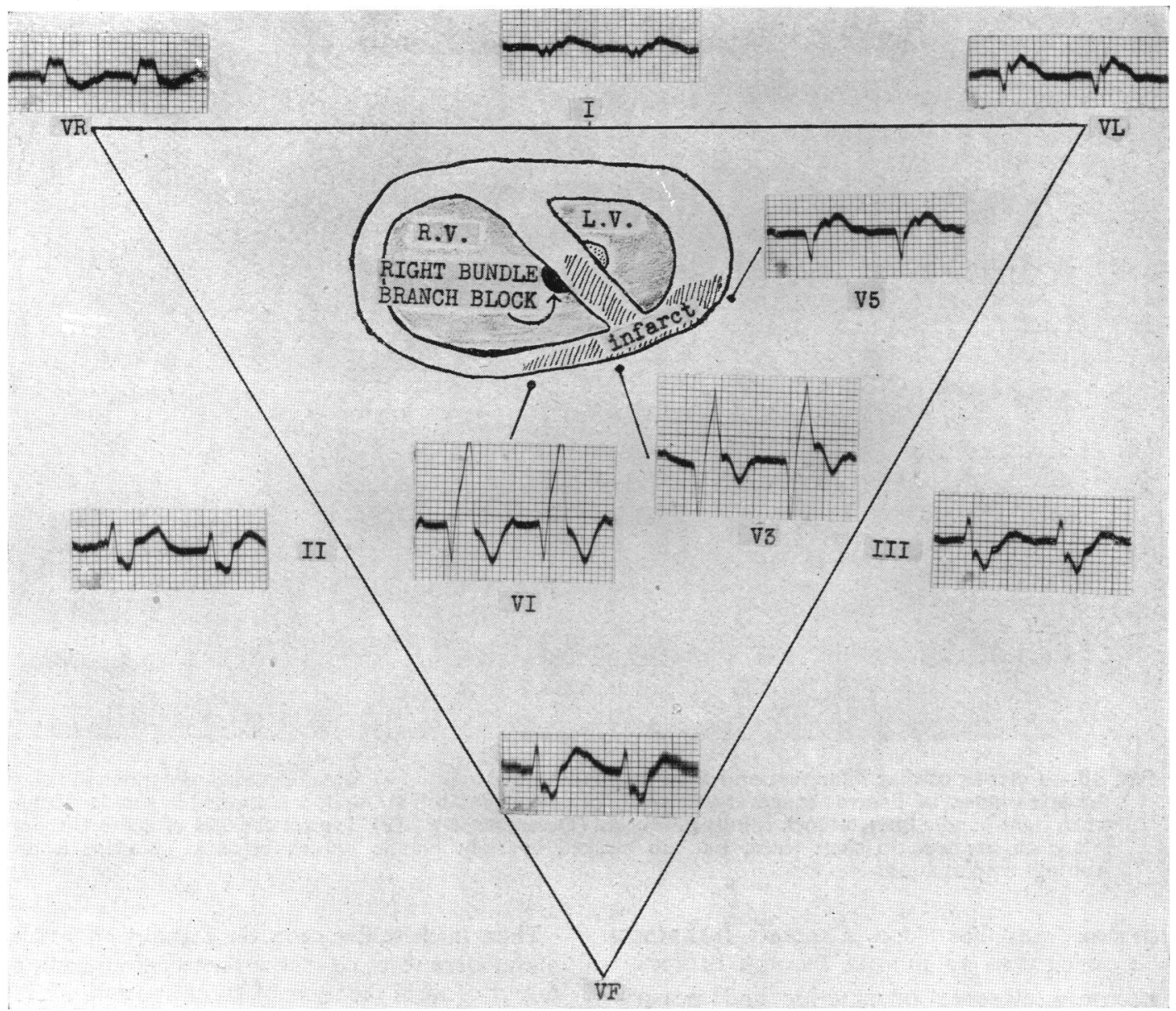

FIG. 9.-Anterior cardiac infarction and right bundle branch block. Characteristic Q waves and RS-T elevation are seen in V3, V5, VL and standard lead I. Autopsy confirmation.

inverted in the fifth case (Fig. 13A). All these records showed indubitable evidence of posterior infarction in other leads.

Some cases with widened and bizarre QRS complexes are the result of fresh infarction distorting the cardiogram of a previous bundle branch block with or without infarction. Alternation of the block between the left and right bundle branches may occur (Master et al., 1938) or the pattern may change permanently from one type of block to another. In this respect Case 46 is of interest. A cardiogram taken in July 1945 showed right bundle branch block with a posterior infarct. Two and a half years later, after another attack of prolonged cardiac pain, from which the patient did not recover, a cardiogram showed left bundle branch block (Fig. 13B). There was no necropsy.
Occasionally, cardiographic evidence of posterior infarction appears to be suppressed by right bundle branch block. This occurred in Case 76, in which the cardiogram showed right bundle branch block with no more than a shallow $Q$ wave in lead III; yet at necropsy the posterior wall of the left ventricle was found to be thinned and fibrosed over a large area. The ventricular septum was not significantly involved. The circumstances that result in suppression of the signs of posterior infarction with right bundle branch block are not clear. We did not feel that a cardiographic diagnosis of infarction could be based on an isolated $Q$ wave in lead III, because this is encountered in 36 per cent of cases of uncomplicated right bundle branch block (Sodeman et al., 1944). 


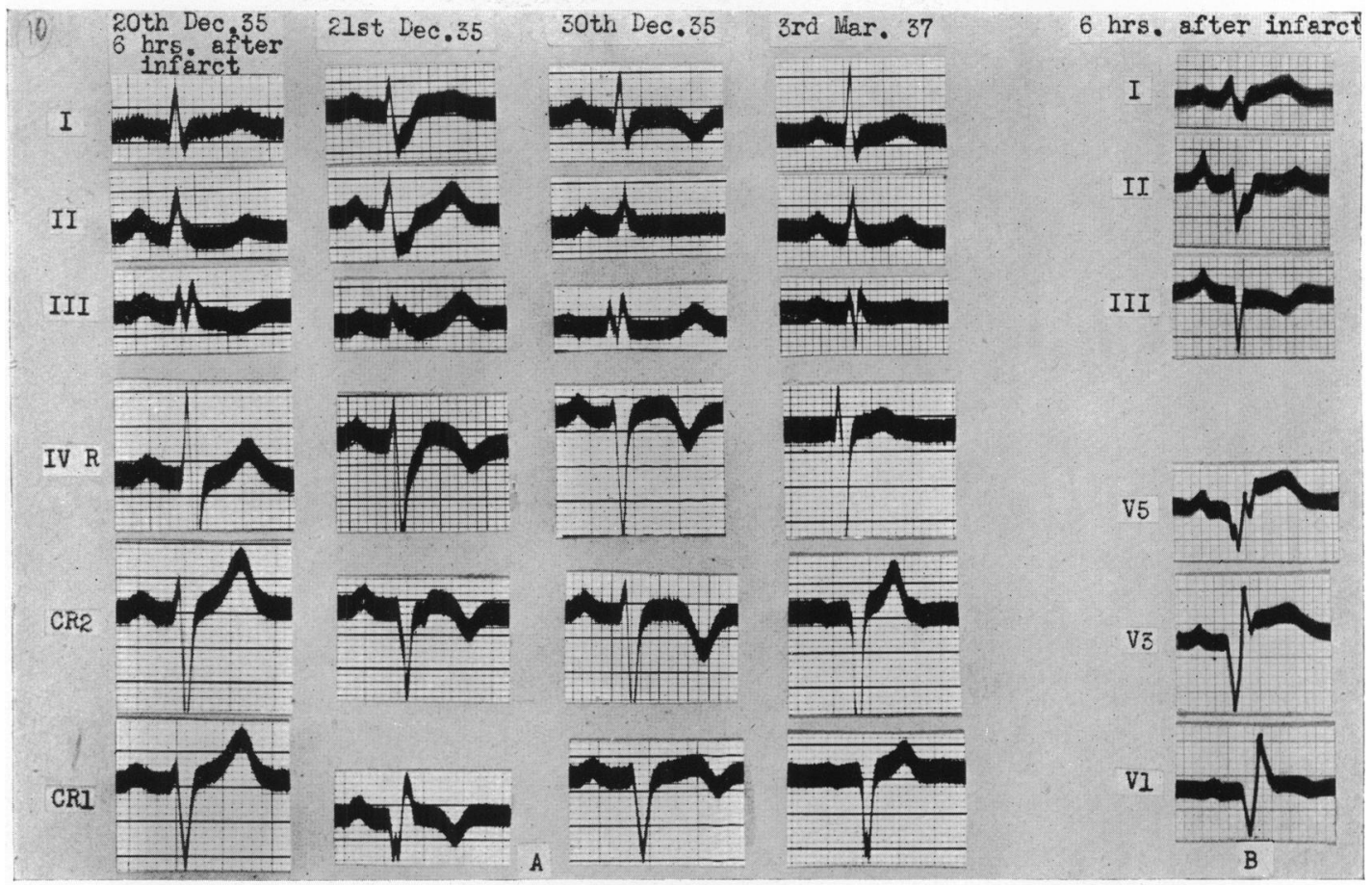

FIG. 10.-Anterior cardiac infarction and right bundle branch block. (A) Serial electrocardiograms showing the development of $T$ wave changes characteristic of anterior infarction: these are masked in standard leads when right bundle branch block is fully developed (December 21). (B) Typical changes of acute anterior infarction are seen in chest leads, but are masked by right bundle branch block in standard leads. Autopsy confirmation.

\section{ANTERIOR AND POSTERIOR CARdiaC INFARCTION} Complicated by Bundle Branch Block

Necropsy evidence of anterior and posterior cardiac infarction was available in five cases in this series, three of them complicated by right and two by left bundle branch block. In four of them the electrocardiogram showed signs of anterior or antero-septal infarction only; three of these had right (Fig. 8 and 11B), and the fourth left bundle branch block (Fig. 1). The anterior infarct in each of these four cases was recent and the posterior infarct old. In the fifth (Fig. 14) a cardiogram taken six hours after the symptoms of a cardiac infarction showed normal intraventricular conduction with $Q$ waves and depressed $S-T$ segments in leads II and III, and abnormally tall $\mathrm{T}$ waves in the chest leads. Five days later, left bundle branch block had developed, as shown in lead CF2; as the heart was vertical, standard leads resemble right bundle branch block. A lead taken over the apex (IV R) was typical of acute anterior infarction. An ante-mortem diagnosis of recent anterior infarction in a vertical heart was made; but at necropsy posterior infarction was also present.
Thus, in these five cases the features of the acute infarct were revealed in the electrocardiogram, and in four of them the signs of an old posterior infarct were suppressed. We have insufficient data, however, to determine the circumstances that result in the dominance of one infarct and the suppression of another.

Pathogenesis of Bundle Branch Block ComPLICATING CARDIAC INFARCTION WITH AN ACCOUNT OF EleVen NeCropsies

It is reasonable to assume that infarction of the ventricular septum might be associated with bundle branch block because of the intimate anatomical relationship between the septum and the bundle branches. In the experimental animal, septal infarction and usually bundle branch block with or without auriculo-ventricular conduction defects may be produced by ligation of the septal artery or of the left coronary artery (Wilson et al., 1944); but the production of bundle branch block by this technique is sometimes unsuccessful (Barton and Greenwood, 1933). In man the findings are similar. When bundle branch block complicates cardiac infarction 

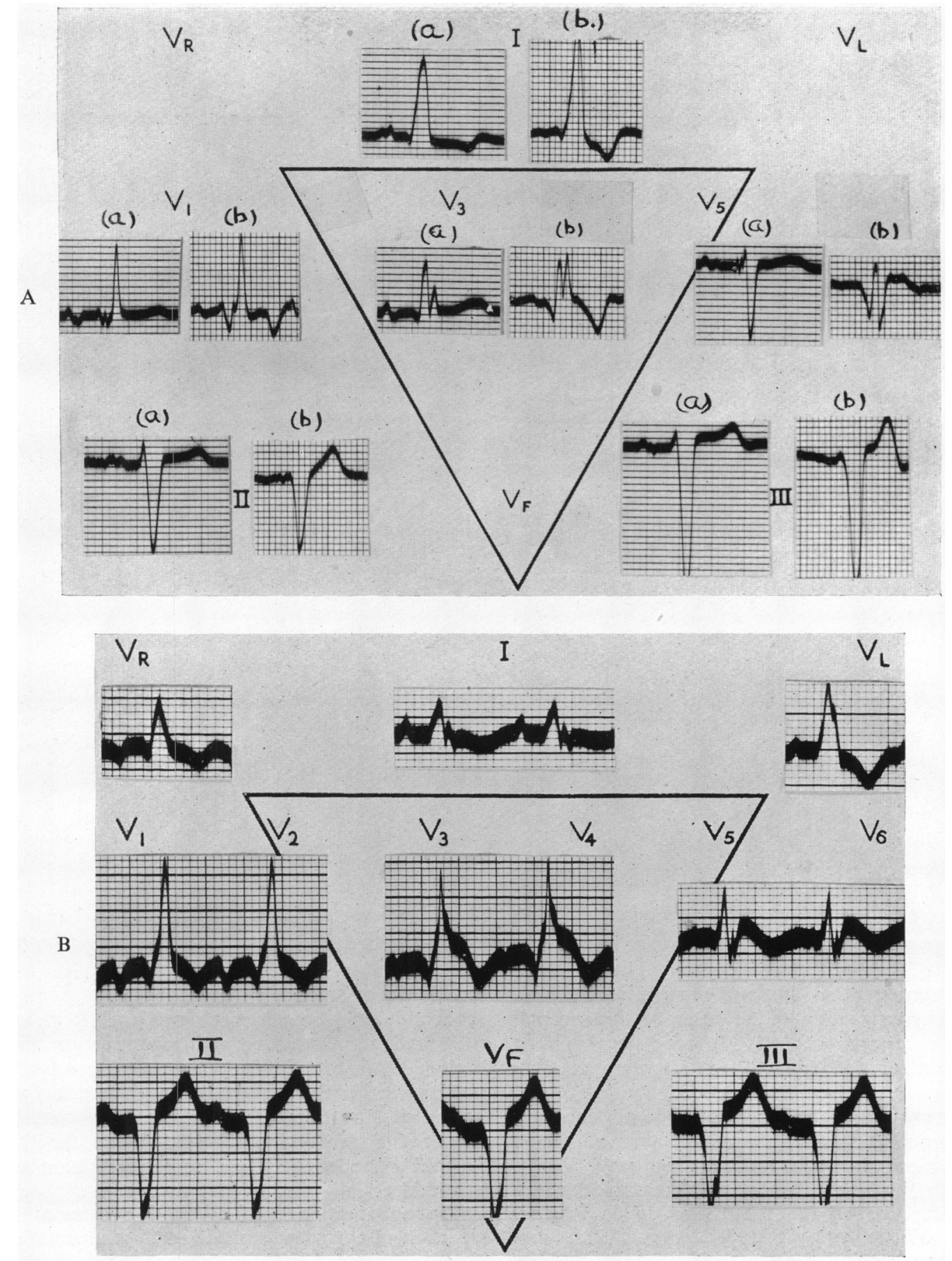

FIG. 11.-Anterior cardiac infarction and right bundle branch block. (A) The control graph (a) was taken on $9 / 9 / 46$, and shows right bundle branch block with a vertical heart. The second curve $(b)$ taken on $24 / 9 / 46$, shows prominent $Q$ waves and inverted $T$ waves in all chest leads due to anterior cardiac infarction. (B) Anterior infarct (11 days old) shown in leads V1 and V3. The right bundle branch block complex in lead V1 is transmitted to lead VL and hence to standard lead I, the heart being electrically vertical. Standard limb leads thus resemble left bundle branch block. 


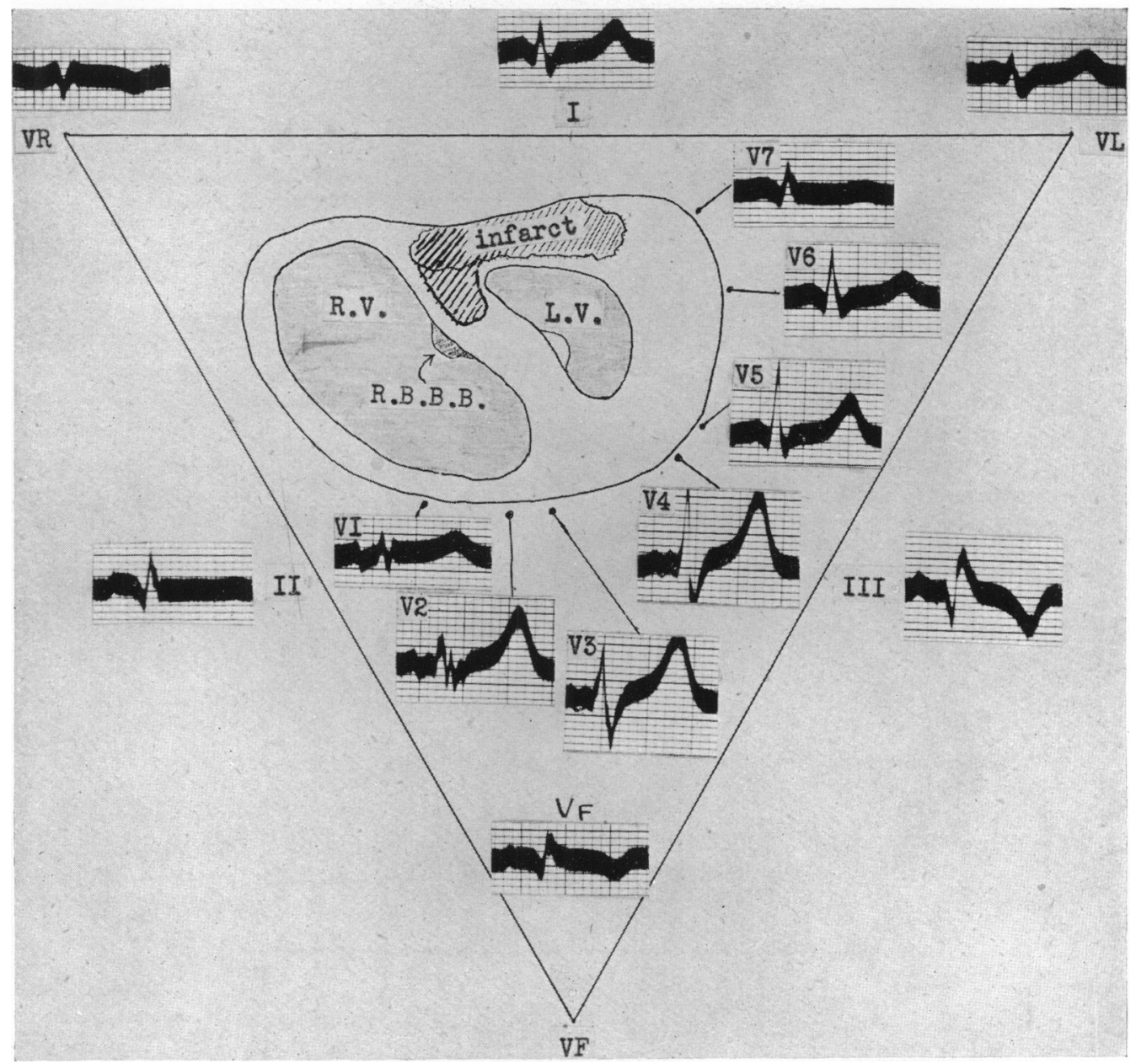

FIG. 12.-Posterior cardiac infarction and right bundle branch block. Pathological $Q$ waves are well seen in lead VF and in standard leads II and III.

the septum is often, but not invariably, involved. In a necropsy study of 30 cases of gross septal infarction, Master et al. (1937) found that impaired intraventricular conduction had been present in only 12 cases.

Attempts to correlate the site of coronary occlusion with the occurrence and type of bundle branch block have been reported frequently (White, 1934; Saphir et al., 1935; Applebaum and Nicholson, 1935; Barnes, 1935; Pratsicas, 1936; Fischer, 1938; Master et al., 1938). Applebaum and Nicholson concluded from their necropsy findings in 11 cases that it was impossible to determine which vessel was occluded by the type of block present; for there was usually severe and extensive involvement of the entire coronary system. Master and his co-workers (1938) also submitted that it was impossible to locate the site of an infarct from the type of bundle branch block present. Reviewing their findings in 20 cases examined at necropsy, these authors reported a similar incidence of conduction defects whether the left or right coronary artery was occluded. In 16 of their 20 cases, however, the infarct did involve the septum. When the QRS interval exceeded 0.14 sec. septal infarction was invariable.

The apparent lack of correlation between the situation of coronary occlusion and cardiac infarction, on the one hand, and bundle branch block on the other might be explained by the presence of a gradually developed collateral circulation in the areas supplied by vessels showing long-standing occlusion (Blumgart and Schlesinger, 1940).

There were 11 necropsies in the present series. 

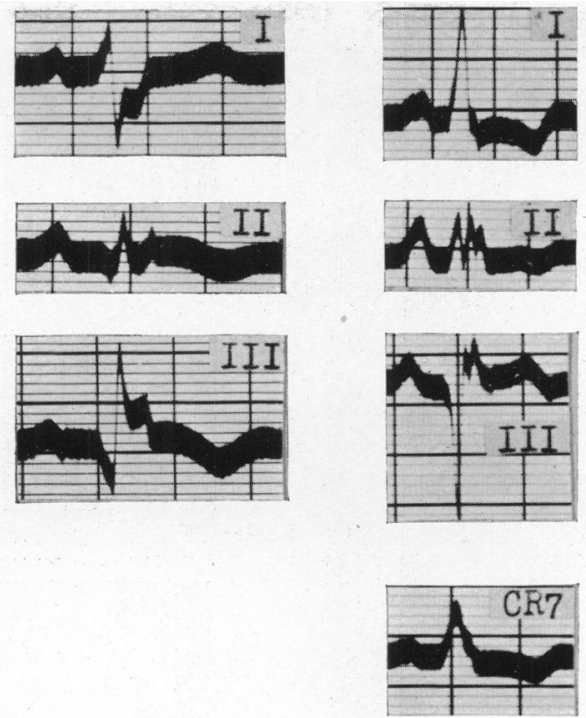

A

B

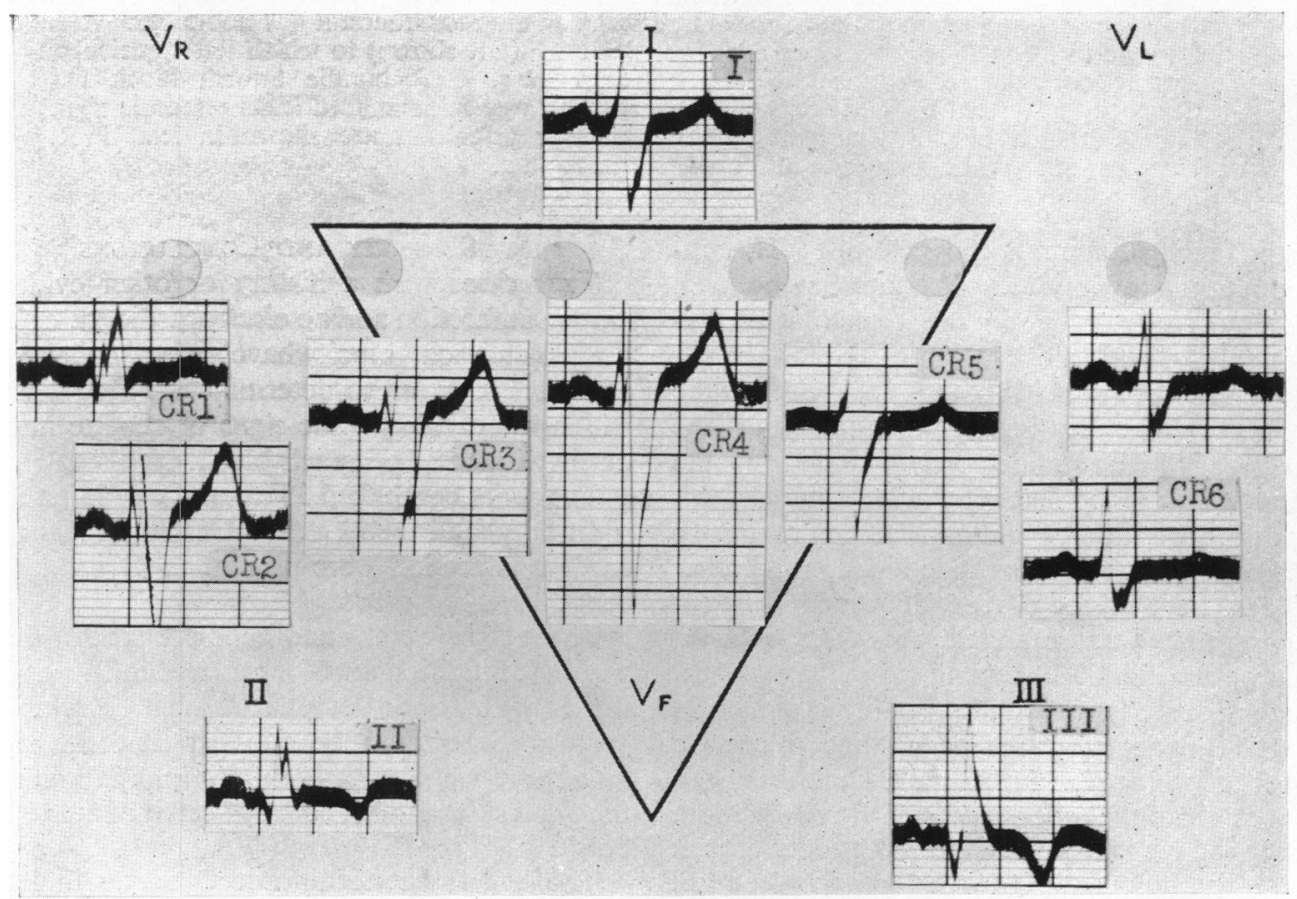

C

Fig. 13.-(A) 9/7/45, showing right bundle branch block and posterior infarction. (B) 11/10/47, showing left bundle branch block after fresh posterior infarction. (C) Posterior cardiac infarction and right bundle branch block. The infarction is shown well in standard leads, but not in lead CR7. 

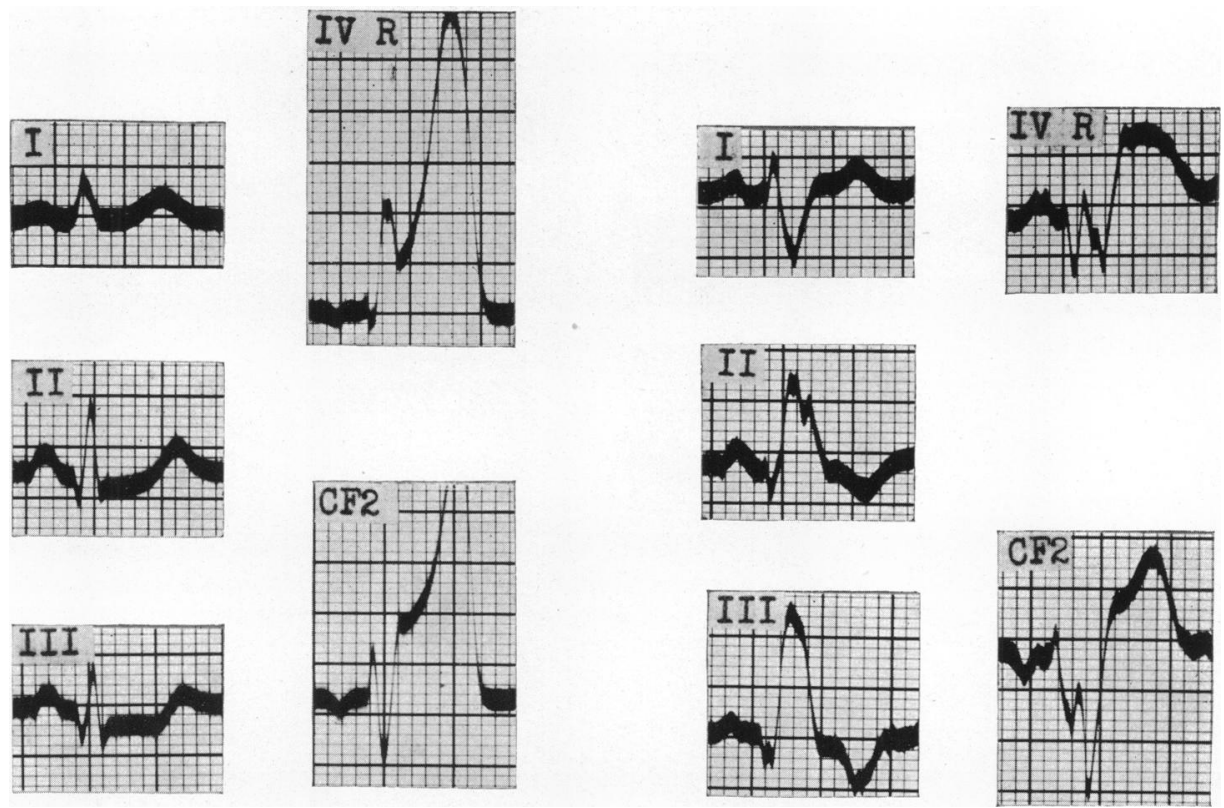

FIG. 14.-Anterior and posterior infarction associated with left bundle branch block in a vertical heart. (A) Normal conduction 6 hours after the onset. Lead 4R shows elevation of the $R-T$ segment and an enormous $T$ wave indicating an anterior infarct a few hours old. The $Q$ wave in leads II and III is derived from lead VF (not shown) to which left ventricular surface potentials are transmitted. (B) 5 days later. Left bundle branch block has developed as shown by lead CF2. The heart being vertical, standard leads resemble right bundle branch block. Changes of acute anterior infarction are shown in lead IVR. Necropsy showed both anterior and posterior infarction.

The main findings, summarized in Table VII, confirm the absence of any clear relationship between the vessel occluded, the bundle branch predominantly involved, and the situation of the infarct.

In 9 cases, however, the infarct involved the ventricular septum. In the 2 instances in which the septum escaped the infarct was situated in the posterior wall of the left ventricle; the electrocardiogram showed left bundle branch block in one (Case 75) and right bundle branch block in the other (Case 76). In 4 of the 9 cases in which the ventricular septum was infarcted, the QRS interval equalled or exceeded $0 \cdot 14$ second.

In a control study we found septal involvement in 58 of 100 unselected cases of cardiac infarction examined at necropsy. From the figures discussed above it is clear that the septum is involved more frequently ( 80 per cent) when there is bundle branch block. If pathological $Q$ waves occurred in all cases of cardiac infarction, left bundle branch block would not therefore be expected to obscure the pattern in 80 per cent of cases. The actual figure of 48 per cent found in our analysis more or less harmonizes with these expectations, for a minority of infarcts are too shallow to cause $Q$ waves.

\section{Summary AND CONClusions}

Sixty cases with a history or other evidence of cardiac infarction and an electrocardiogram showing bundle branch block have been collected and analysed in order to determine the frequency with which the cardiographic signs of cardiac infarction occur with bundle branch block.

The series comprised 33 examples of left and 27 of right bundle branch block. Cardiographic signs of cardiac infarction were present in 41 cases (68 per cent).

These signs were found in 48 per cent of the cases with left bundle branch block, and in 93 per cent of those with right bundle branch block. As a corollary it should be stressed that the signs of infarction were suppressed in approximately half the cases complicated by left bundle branch block.

The belief that significant $Q$ waves in left ventricular surface leads in cases with left bundle branch block denote septal infarction is supported by limited necropsy evidence.

In the presence of left bundle branch block, the signs of anterior infarction were revealed as frequently with standard limb leads as with multiple 
chest leads and unipolar limb leads. In the presence of right bundle branch block, signs of anterior infarction were sometimes seen only in the chest leads.
The signs of posterior infarction were practically confined to the standard limb leads and to lead VF whether the block was in the left or right bundle branch.

TABLE VII

Necropsy Findings in Eleven Cases of Cardiac Infarction and Bundle Branch Block

\begin{tabular}{|c|c|c|c|c|}
\hline \multirow{2}{*}{$\begin{array}{l}\text { Case } \\
\text { No. }\end{array}$} & \multicolumn{3}{|c|}{ Electrocardiogram } & \multirow[b]{2}{*}{ Necropsy } \\
\hline & $\begin{array}{l}\text { QRS } \\
\text { (sec.) }\end{array}$ & Block & Infarct & \\
\hline 1 & $0 \cdot 14$ & Left & Anterior & $\begin{array}{l}\text { Arteries. Generalized severe atheroma. No thrombosis discovered. } \\
\text { Infarct. Recent infarction of anterior wall of left ventricle and upper three- }\end{array}$ \\
\hline 8 & $0 \cdot 12$ & Left & Anterior & $\begin{array}{l}\text { Arteries. Slight atheroma of main vessels. Smaller sub-divisions showed } \\
\text { diffuse widespread atheroma. No occlusion. } \\
\text { Infarct. Anterior wall of left ventricle and ventricular septum. Diffuse } \\
\text { fibrosis involving left ventricle and ventricular septum. }\end{array}$ \\
\hline 10 & 0.12 & Left & Anterior & $\begin{array}{l}\text { Arteries. Calcified atheroma marked in main arteries. Left anterior descend- } \\
\text { ing branch and right coronary completely occluded by organized thrombus. } \\
\text { The left circumflex partially occluded by calcified atheroma. } \\
\text { Infarct. Extensive old infarction of anterior and posterior walls of left ventricle } \\
\text { and ventricular septum. Recent infarction involving anterior wall and ven- } \\
\text { tricular septum. Widespread subendocardial fibrosis of left ventricle. }\end{array}$ \\
\hline 20 & $0 \cdot 12$ & Right & Anterior & $\begin{array}{l}\text { Arteries. Both right and left coronaries completely occluded and calcified for a } \\
\text { distance of } 1-2 \mathrm{~cm} \text {. commencing } 2 \mathrm{~cm} \text {. beyond their origin. } \\
\text { Infarct. Extensive recent infarction involving postero-inferior two-thirds of ven- } \\
\text { tricular septum, apex and lower one-third of anterior wall of left ventricle. } \\
\text { Whole thickness of anterior wall partially necrotic. Old infarction in posterior } \\
\text { wall of left ventricle. }\end{array}$ \\
\hline 21 & $0 \cdot 12$ & Right & Anterior & $\begin{array}{l}\text { Arteries. Left anterior descending and right coronary arteries occluded. } \\
\text { Infarct. Recent extensive infarction involving anterior wall of left ventricle and } \\
\text { ventricular septum. Old infarction of posterior wall of left ventricle. }\end{array}$ \\
\hline 23 & $0 \cdot 16$ & Right & Anterior & $\begin{array}{l}\text { Arteries. Generalized atheroma. Anterior descending branch of left coronary } \\
\text { thrombosed in proximal } 3 \mathrm{~cm} \text {; distal part was laminated and calcified and } \\
\text { proximal part fresh and homogeneous. } \\
\text { Infarct. Apex of left ventricle and lower part of ventricular septum recently } \\
\text { infarcted. }\end{array}$ \\
\hline 28 & $0 \cdot 16$ & Right & Anterior & $\begin{array}{l}\text { Arteries. Anterior descending branch of left coronary occluded in proximal } \\
2 \mathrm{~cm} \text {. Left main coronary and circumflex branch normal. Moderate } \\
\text { atheroma of right coronary. } \\
\text { Infarct. Recent infarction of anterior wall of left ventricle and of ventricular } \\
\text { septum. }\end{array}$ \\
\hline 30 & $0 \cdot 12$ & Right & Anterior & $\begin{array}{l}\text { Infarct. Recent extensive infarction of anterior wall of left ventricle and of } \\
\text { ventricular septum. Old fibrosed infarction of posterior wall of left ventricle. }\end{array}$ \\
\hline 49 & $0 \cdot 16$ & Right & $\begin{array}{l}\text { Anterior } \\
\text { and Pos- }\end{array}$ & $\begin{array}{l}\text { Infarct. Recent infarction of apex and anterior and posterior walls of left } \\
\text { ventricle and of ventricular septum. }\end{array}$ \\
\hline 75 & $0 \cdot 12$ & Left & & $\begin{array}{l}\text { Arteries. Marked atheroma of entire coronary tree. Thrombosis of circum- } \\
\text { flex branch of left coronary. }\end{array}$ \\
\hline 76 & 0.12 & Right & - & $\begin{array}{l}\text { Infarct. Large area of posterior wall of left ventricle recently infarcted. } \\
\text { Infarct. Thinning and fibrosis of old infarction involving posterior wall of left } \\
\text { ventricle. }\end{array}$ \\
\hline
\end{tabular}

\section{REFERENCES}

Applebaum, E., and Nicholson, G. H. B. (1935). Amer. Barton, E. M., and Greenwood, H. H. (1933). Arch. Heart J., 10, 662.

Bach, F. (1930). Quart. J. Med., 23, 261.

Barnes, A. R. (1935). Arch. intern. Med., 55, 457. Path., 16, 15.

Blumgart, H. L., and Schlesinger, M. J. (1940). Amer. Heart J., 19, 1. 
Carlotti, J. (1947). Arch. Mal. Caur., 40, 99.

Comeau, W. J., Hamilton, J. G. M., and White, P. D. (1938). Amer. Heart J., 15, 276.

Dressler, W. (1943). Amer. J. med. Sci., 206, 361.

Evans, W., and Hunter, A. (1943). Brit. Heart J., $5,73$.

Fischer, R. (1938). 'Arch. Mal. Caur., 31, 997.

Goldberger, E. (1947). Unipolar Lead Electrocardiography, Philadelphia.

Hill, I. G. W. (1934). J. Physiol., 81, 70.

Master, A. M., Dack, S., and Jaffe, H. L. (1938). Amer. Heart J., 16, 283. (1937). New York State J. Med., 37, 1707.

Moia, B., and Acevedo, H. J. (1945). Rev. argent. Cardiol., 11, 341.

Mortensen, V. (1940). Aet. med. Scand., 104, 267.

Nordenfelt, O. (1939). Ibid., 102, 101.

Oppenheimer, B. S., and Rothschild, M. A. (1917). J. Amer. med. Assoc., 69, 429.

Pratsicas, A. (1936). Arch. Mal. Caur., 29, 455.

Saphir, O., Priest, W. S., Hamburger, W. W., and Katz, L. N. (1935). Amer. Heart. J., 10, 567.
Simonson, E., Enzer, N., and Goodman, J. S. (1945). Amer. J. med. Sci., 209, 349.

Sodeman, W. A., Johnston, F. D., and Wilson, F. N. (1944). Amer. Heart J., 28, 271.

Vela, M. (1944). Valor Pronostico del Electrocardiograma, Madrid.

White, P. D. (1934). Amer. Heart J., 10, 260.

Wilson, F. N., and Hermann, G. R. (1921). Heart, 8, 229.

-, Johnston, F. D., Hill, I. G. W., Macleod, A. G., and Barker, P. S. (1934a). Amer. Heart J., 9, 459. (1936). The Electrocardiogram in Diseases of the Coronary Arteries in Diseases of the Coronary Arteries and Cardiac Pain. (Robert Levy.) New York.

-, Hill, I. G. W., and Johnston, F. D. (1934b). Amer. Heart J., 9, 596.

- Johnston, F. D., Rosenbaum, F. F., Erlanger, H., Kossmann, C. E., Hecht, H., Cotrim, N., De Oliveira, R. M., Scarsi, R., and Barker, P. S. (1944). Amer. Heart J., 27, 19.

-, Rosenbaum, F. F., and Johnston, F. D. (1947). Advances in Internal Medicine, vol. 2, New York. 